\title{
Análisis microbiológico en macerados de la mosca doméstica musca domestica como portador de agentes microbianos en el restaurante la venada de la Universidad Surcolombiana sede central Neiva - Huila
}

\author{
Luis Evelio Javela Másmela \\ Estudiante Universidad Surcolombiana, Colombia \\ l.e.j.m._13@hotmail.com \\ Rosa Alcira Carreño Ruíz \\ Universidad Surcolombiana, Colombia \\ Rositakbolivar@hotmail.com
}

\section{Resumen}

Mundialmente, este insecto es un vector de agentes patógenos y un transmisor comprobado de 30 virus, 175 bacterias, 8 especies de espiroquetas, 3 rickettsias, entre otros. Musca doméstica es atraída por sustratos, alimentos, y desperdicios convirtiéndola en un vector eficiente de patógenos. El objetivo del estudio es estimar los tamaños poblacionales de los microorganismos en la M. doméstica, evaluar el papel como vector en el transporte de enterobacterias de importancia para la salud pública, comparar las vías de contaminación (alimentos-vector) de los productos alimenticios y concientizar a la comunidad educativa en normas básicas de asepsia. Realizándose en tres etapas.

Durante la primera etapa, se capturan de los individuos en trampas artesanales con cloroformo. Para el análisis microbiológico de enterobacterias, se procede a sembrar por agotamiento, el macerado en agar MacConkey y agar sangre, durante 24 horas a $37^{\circ} \mathrm{C}$. Se efectúa la tinción de Gram para la determinación de la morfología de colonia y la morfología celular. Para la identificación y confirmación de bacterias, se realizarán pruebas de biología molecular convencionales PCR. Para la comparación de las vías de contaminación (alimentos-vector) se realiza una triangulación del estudio terminado de alimentos expendidos en el restaurante y el vector. Para concientizar a la comunidad universitaria en el manejo de las técnicas correctas de asepsia en el manejo y preparación de los alimentos, así como las enfermedades que produce el vector se divulgará la información recolectada mediante una cartilla o folletos.

Palabras clave: Análisis microbiológico, macerado, mosca doméstica, prueba de biología molecular PCR y trampa artesanal.

\section{Microbiological analysis in macerates of domestic fly musca domestica as carrier of microbial agents in the restaurant la Venada of the Universidad Surcolombiana headquarters Neiva - Huila}

\section{Abstract}

This insect is a vector of pathogenic agents and a verified transmitter of 30 virus, 175 bacteria, 8 species of spirochetes, 3 rickettsia, between others, throughout the world. Domestic Musca is attracted by substrata, food, and wastes turning her into an efficient vector of pathogenic. The aim of 
the study is estimate of the population sizes of the microorganisms in M. domestic, to evaluate the paper as vector in the transport of enterobacterias of importance for the public health, to compare the routes of pollution (food - vector) of the food products and sensitize to the educational community in basic procedure of asepsis. Being realized in three stages.

During the first stage, they are captured of the individuals in handcrafted traps by chloroform. For the microbiological analysis of enterobacterias, it will proceed to sow by depletion, the softened one in agar MacConkey and agar blood, for 24 hours to $37^{\circ} \mathrm{C}$. Gram's tint will be effected for the determination of the morphology of colony and the cellular morphology. For the identification and confirmation of bacteria, PCR will realize conventional tests of molecular biology. For the comparison of the routes of pollution (food - vector) there will be realized a triangulation of the study finished of food expended in the restaurant and the vector. To sensitize to the university community in the managing of the correct technologies of asepsis in the managing and preparation of the food, as well as the diseases that the vector produces one will spread the information gathered by means of a primer or leaflets.

Keywords: Microbiological analysis, softened, domestic fly, molecular biology test PCR, and handcrafted trap.

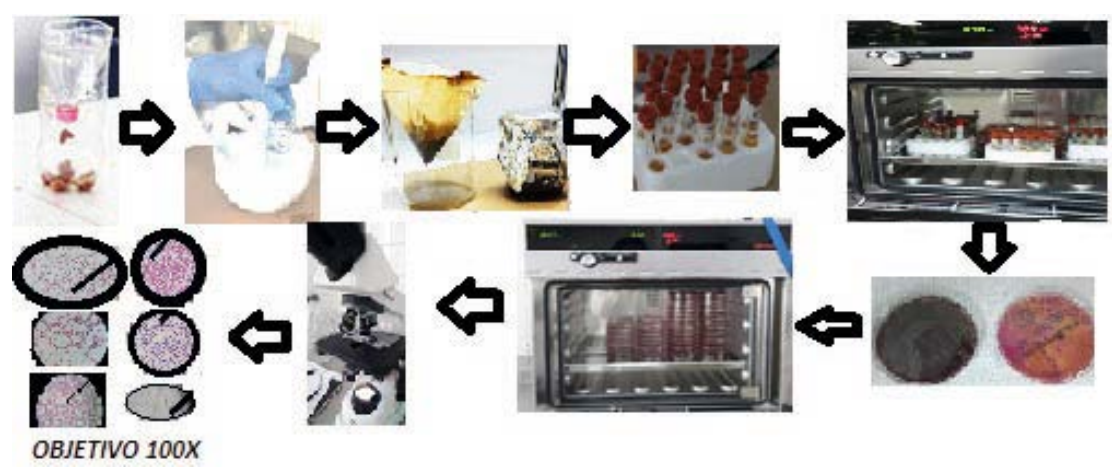

Figura 1. Procedimiento para el análisis microbiológico de la mosca. Fuente: Elaboración propia, 2017.

\section{Introducción}

Las infestaciones por miembros del Orden Díptera, tanto en los animales domésticos como en el ser humano, son de gran importancia debido a las pérdidas económicas que conlleva, al provocar la disminución del rendimiento de productos y subproductos de origen animal. En el expendio público de alimentos en Colombia, se encuentra la frecuente interacción de la mosca y los humanos. Mundialmente, se conoce a este insecto, como vector de agentes patógenos y con la concentración en áreas urbanas de las poblaciones humanas, este riesgo se ha aumentado. Las moscas, se consideran importantes vectores de infecciones entéricas, que afectan a personas y a los animales domésticos. Esta es un transmisor comprobado de más de 30 virus, 175 bacterias, 8 especies de espiroquetas, 3 rickettsias, 19 hongos, más de 30 protozoarios y numerosos helmintos. (Bejar V., et al., 2006)

La Organización Mundial de la Salud plantea que la mayoría de las contaminaciones de alimentos quegeneranenfermedades transmitidas por alimentos ocurren por problemas sanitarios y de manipulación, dentro del hogar y en sitios en donde se elaboran para la venta. (Almeida, C. 1996).

Las Enfermedades Transmitidas por los alimentos (ETAs) ocupan el segundo lugar entre las diez primeras causas de morbimortalidad en el mundo, y según la OMS (1996) el 70\% de los casos reportados corresponden a diarreas. El nivel de salud de la población está relacionado directamente con la higiene y seguridad de los alimentos que puedan adquirirse (Gambirazio, 
2002). Se considera que las comunidades propias de áreas climáticas con predominio de altas temperaturas, con malos hábitos de higiene, tienen mayor riesgo de contraer algunas ETAs (Almeida, C. 1996).

Los principales agentes etiológicos de las diarreas son los virus, protozoarios y bacterias, la más frecuentes pertenecen a los géneros de Salmonella, Shigella, Escherichia y Vibrio, las cuales pueden transmitirse por la vía anomano-boca o por la ingesta de alimentos y aguas contaminadas (Bonifaz A., 2010). La preparación y manipulación de los alimentos son factores claves en el desarrollo de las ETAs, por lo que la actitud de los consumidores resulta muy importante para prevenirlas.

El presente trabajo pretende establecer y demostrar los riesgos microbiológicos de ambientes en donde concurre la mosca doméstica. El objetivo de este estudio es evaluar el papel de las moscas como vector en el transporte de enterobacterias y otros microorganismos de importancia en la salud pública. Para ello se realizará en tres fases un estudio descriptivo del restaurante La Venada de la Universidad Surcolombiana sede Neiva - Huila. La población universo corresponderá a las moscas presentes en el servicio de alimentación del restaurante La Venada de la U. Surcolombiana sede Central Neiva - Huila, en donde se practicará análisis microbiológico, correspondiente a la determinación de enterobacterias, y su posterior verificación por medio de pruebas de biología molecular PCR.

\section{Metodología}

El presente trabajo de investigación se realizará en tres etapas. Durante la primera etapa se procederá a la captura y recolección durante tres días (entre semana) del espécimen a estudiar $(M$. domestica) en el sector del restaurante La Venada de la Universidad Surcolombiana sede central Neiva - Huila y en diferentes lugares como la cafetería y el restaurante de la sede Salud.

Los respectivos especímenes, se recolectarán por medio de una trampa elaborada

artesanalmente con frascos de gaseosa (como se muestra en la figura 1), las cuales serán ubicadas en el sitio específico donde se consumen los alimentos y que cumplan con los criterios de inclusión y no hagan parte de los criterios de exclusión.

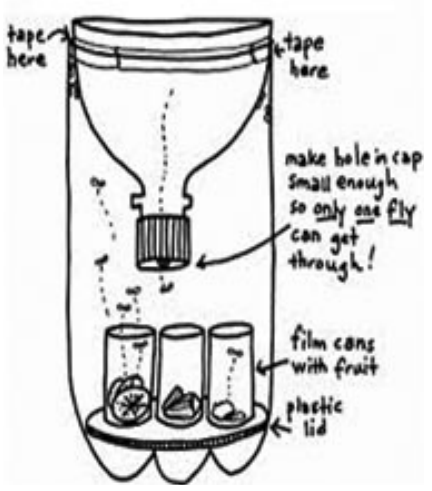

Figura 2. Trampa artesanal con frasco de gaseosa. Fuente: Graczyk, et al.; 2005. moscas que no pertenezcan al lugar de estudio y moscas que no tengan adecuada manipulación durante su recolección, es decir, que no estén en las trampas artesanales, o que no sean llevadas directamente al laboratorio para su estudio, con su respectiva rotulación.

Antes de iniciar la recolección de las moscas se procederá a cuantificar el índice de infestación de la zona de recolección de acuerdo con los siguientes intervalos:

- Índice de infestación bajo: $<5$ moscas/hora de observación.

- Índice de infestación mediano: 5 - 15 moscas/ hora de observación.

- Índice de infestación alto: > 20 moscas/hora de observación (Basualdo W., et, al. 2001)

Los individuos a estudiar serán sacrificados con cloroformo y separados en tubos de ensayo con seis a diez ejemplares cada uno. Para el macerado de las moscas, se lavan los especímenes con 2 $\mathrm{mL}$ de agua destilada estéril con movimientos de agitación por cinco minutos, se deja reposar por diez minutos y se elimina el sobrenadante, con los especímenes libres de agua destilada, se 
realiza un macerado de las moscas con la ayuda del extremo posterior de un hisopo estéril hasta lograr una masa uniforme. Se agrega $1 \mathrm{~mL}$ más de agua destilada para homogeneizar la mezcla obtenida, se cultivan por separado el sedimento y sobrenadante de la mezcla en los medios de cultivos respectivos.

Análisis microbiológico de la determinación de enterobacterias

Para este análisis, se efectuó una siembra de la muestra (macerado de 120 moscas capturadas) en caldo nutritivo enriquecido; del cual se filtran del macerado $15 \mathrm{ml}$ de extracto final con papel filtro y se distribuye de la siguiente manera: 10 primeros tubos de ensayo con $1 \mathrm{ml}$ de extracto, del 11 al 15 con $0,5 \mathrm{ml}$ de extracto, y del 16 al 20 con $0,5 \mathrm{ml}$ de macerado precipitado y del 21 al 25 con $1 \mathrm{ml}$ del macerado precipitado, se lleva a la incubadora a $37^{\circ} \mathrm{C}$ durante 24 horas.

Posteriormente, siembra por agotamiento, el macerado de los insectos, en diferentes medios de cultivo bacteriano, como son agar MacConkey Biomerieux(agarselectivo para30enterobacterias) y agar sangre Biomerieux (medio de cultivo enriquecido recomendado para el aislamiento y desarrollo de bacterias Gram-positivas y Gram negativas), se incuba durante 24 horas a $37^{\circ} \mathrm{C}$. Luego, se efectúa el análisis de la morfología de la colonia y la coloración de Gram para determinar la morfología bacteriana. Para realizar la tinción de Gram se toma una muestra pequeña de la colonia y se esparce en un portaobjeto, se deja secar a temperatura ambiente y se fija al calor con mechero. Se agregan los colorantes de Gram en su orden y con los tiempos ya estandarizados. Finalmente se adiciona una gota de aceite de inmersión y se lleva al microscopio para hacer la observación del microorganismo con el objetivo de 100x.

\section{Identificación de bacterias}

La tercera etapa es la identificación de bacterias (género), se realiza la descripción de las características de su morfología celular y la morfología de colonia en agar MacConkey y Sangre.
La confirmación de los géneros estudiados se realizará mediante las técnicas convencionales o prueba de PCR.

Paralacomparacióndelasvíasdecontaminación (alimentos-vector) de los productos alimenticios que se sirven en el restaurante, se realizará una triangulación de datos a partir de los estudios culminados de los alimentos expendidos en el restaurante y en los alrededores como cafetería y ventas ambulantes.

Para reconocer el efecto que producen estos microorganismos en la salud humana, se concientizará a la comunidad frente a los efectos que tienen estos microorganismos en el cuerpo, cuáles son sus enfermedades, que pasa cuando no se tratan a tiempo las enfermedades que estos producen, para así saber cuáles son las medidas de asepsia y limpieza que deben tener las personas que trabajan o manipulan los alimentos en el restaurante La Venada, y su preparación.

Para concientizar a la comunidad universitaria en el manejo de las técnicas correctas de asepsia en el manejo y preparación de los alimentos, que prevengan la contaminación de los alimentos que se consumen al hacer uso del servicio de alimentación en el restaurante estudiantil La Venada, se trabajará en conjunto con Bienestar Universitario al hacer una campaña masiva divulgando la información recolectada de este proyecto de investigación mediante una cartilla o panfletos invitando a toda la comunidad universitaria donde se mostrarán sus enfermedades y los datos producidos en esta investigación.

Durante los 6 meses en que transcurrió el proyecto se realizaron muestreos regulares entre semana (lunes, miércoles y viernes), se hizo la colecta final o captura de las respectivas moscas de cada uno de los sitios estudiados (restaurante La Venada) y como control el restaurante de la sede de Salud. En total se recolectaron 120 ejemplares de $\mathrm{M}$. doméstica, solo el número de muestras recolectado fue del restaurante La Venada. Luego estos se procesaron en un mortero macerándolas durante un minuto para formar una mezcla compacta del material. Se agregó $2 \mathrm{ml}$ 
de agua destilada estéril y luego se recolectó todo el contenido en un beaker el cual se trasvaso del mortero al beaker con ayuda de un papel filtro el cual separo el líquido sobrenadante del macerado. Del proceso del macerado se obtuvieron $15 \mathrm{ml}$ de filtrado del macerado, y $3 \mathrm{ml}$ de macerado.

Luego se recolectaron en 25 tubos de ensayo los cuales se distribuyeron de la siguiente manera: Tubo muestra \#1 al tubo muestra \#10 con $1 \mathrm{ml}$ del filtrado del macerado, tubo muestra \#11 al tubo muestra \#15 con $0,5 \mathrm{ml}$ del filtrado del macerado, tubo muestra \#16 al tubo muestra \#20 con 0,5 ml del macerado, y del tubo muestra $\# 21$ al tubo muestra \#25 con $1 \mathrm{ml}$ del macerado. Se llevaron a una incubadora a $37^{\circ} \mathrm{C}$ durante 24 horas.

\section{Recolección de muestras en el restaurante la Venada:}

Estratégicamente se ubicaron las trampas por cada esquina en el área del restaurante, bajo el mesón donde se sirven los alimentos, bajo algunas mesas, en las esquinas del servicio de restaurante. En general, las trampas se dispusieron así:

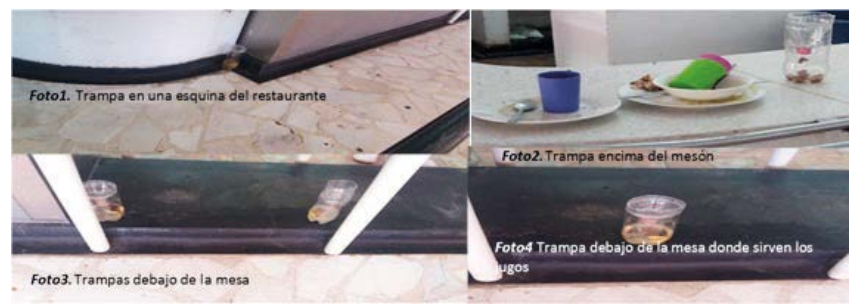

Figura 3. Trampas artesanales elaboradas con frascos de gaseosa. Fuente: Elaboración propia, 2017.

Elaboración de las trampas artesanales:

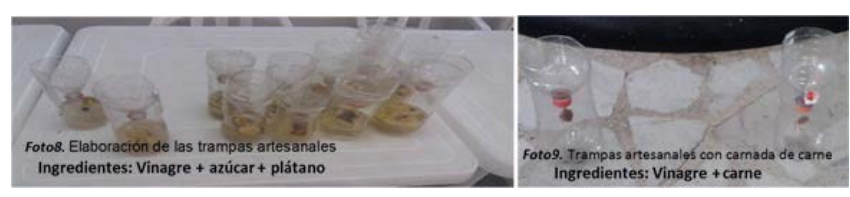

Figura 4. Trampas artesanales elaboradas con frascos de gaseosa. Con sus respectivos ingredientes. Fuente: Elaboración propia, 2017.

Para la elaboración de las trampas artesanales, lo primero que se hizo fue la recolecta de 30 frascos de gaseosa de 1,75 ml.

Procesamiento de la muestra (macerado, filtración, siembra en caldo nutritivo, incubación durante 24 horas):

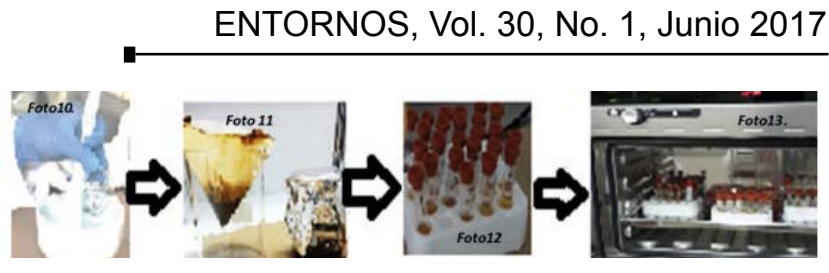

Figura 5. Procesamiento de la muestra (moscas) en su orden: Macerado, filtración, siembra en caldo nutritivo, incubación $24 \mathrm{~h}-37^{\circ} \mathrm{C}$. Fuente: Elaboración propia, 2017.

Después de incubadas las muestras a $37^{\circ} \mathrm{C}$ durante $24 \mathrm{~h}$, las llevamos estas a repicar en los agares MacConkey y agar sangre, sembrando cada muestra en el medio por la técnica de agotamiento.

Foto 14

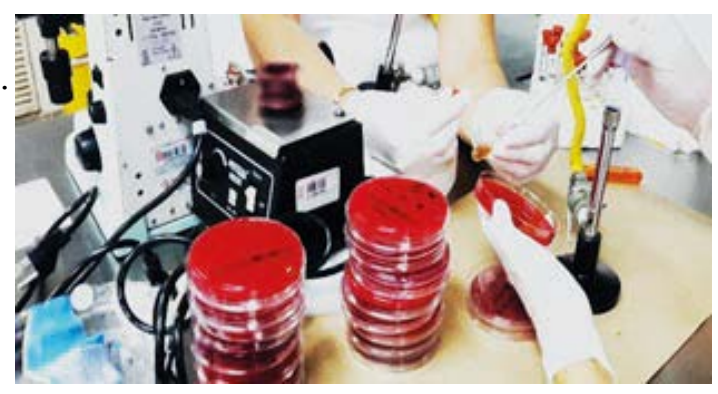

Figura 6. Siembra en agar sangre por agotamiento. Fuente: Elaboración propia, 2017.

En los medios de cultivo MacConkey y Agar Sangre observamos que en la mayoría de ellos se ve crecimiento bacteriano de E. Coli, Klebsiella, Proteus, Salmonella, entre otros. La característica principal de cada medio es el cambio de color de la colonia de acuerdo si es fermentadora de lactosa o no. Para el caso del agar MacConkey se ve crecimiento de una especie fermentadora por el color rosado o fucsia que presentan y las no fermentadoras son colonias de color amarillo verdoso, para el agar Sangre solamente se observa el crecimiento y la morfología de la colonia.

Para purificar la bacteria, se toma una pequeña muestra de la colonia y se siembra por agotamiento en el agar MacConkey, que es un medio diferencial para gérmenes Gram negativos, lo cual nos ayuda a tener más especificidad del microorganismo y facilita su identificación al estar puro.

Se toma de cada colonia encontrada en los diferentes medios, una muestra con ayuda de un hisopo estéril se coloca sobre una lámina 
portaobjeto, se deja secar a temperatura ambiente y se fija al calor, luego se colorea con colorante de Gram. Finalmente, se le agrega una gota de aceite de inmersión y se observa en el microscopio con el objetivo de 100x, obteniéndose:
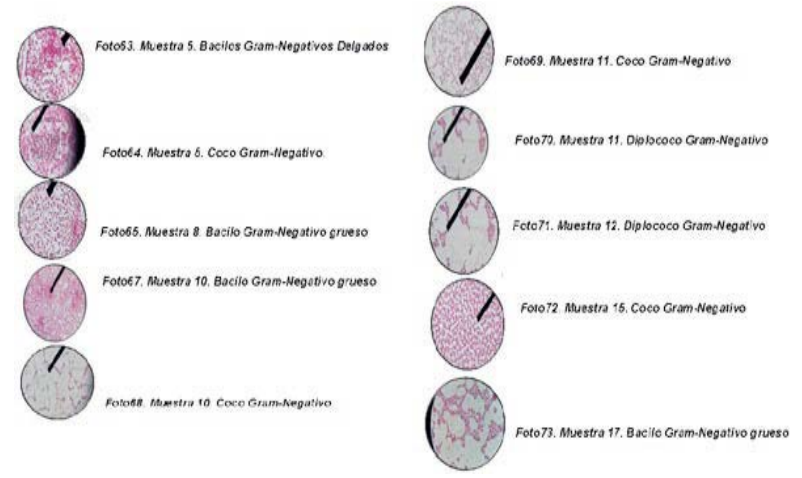

Figura 7. Observación de las muestras al microscopio. Objetivo100x. Fuente: Elaboración propia, 2017.

Fase \#2: Para la segunda fase se delimitó solo el macerado de una parte de la mosca, en este caso las patas del insecto.

Para esta fase se procede de igual manera que en la fase anterior, se hizo la colecta o captura de las respectivas moscas de cada uno de los sitios estudiados (restaurante La Venada). En total se recolectaron 22 ejemplares de $M$. doméstica. Luego estos se procesaron en un mortero macerando solo las patas durante un minuto para formar una mezcla compacta del material. Se agregó $2 \mathrm{ml}$ de agua destilada estéril y luego se recolectó todo el contenido en un beaker el cual se recogió 2,7 $\mathrm{ml}$ final de sobrenadante del macerado y se trasvasó del mortero al beaker con ayuda de un papel filtro. Del proceso del macerado se obtuvo 2,7 ml de sobrenadante el cual se sembró. Luego se recolectó el macerado obtenido en 25 tubos de ensayo los cuales se sembraron y distribuyeron de la siguiente manera: Tubo muestra \#1 al tubo muestra \#20 con 50 uL del filtrado del macerado, tubo muestra \#21 al tubo muestra \#23 con $10 \mathrm{uL}$ del filtrado del macerado, tubo muestra \#24 con 15 uL del macerado, y el tubo muestra \#25 con $1 \mathrm{ml}$ del macerado. Después se llevaron a una incubadora a $37^{\circ} \mathrm{C}$ durante 24 horas. Se repican en Agar MacConkey por la técnica de agotamiento. Se continúa con el mismo procedimiento de la fase \# 1 .
Fase \#3: Finalmente, la tercera fase consiste en la identificación de cada microorganismo por pruebas convencionales y de biología molecular, PCR.

Como medio de transporte utilizamos AMIES con carbón activado.

Tomamos la totalidad del cultivo, de cada una delas muestras recolectadas en las fases anteriores, con ayuda de un escobillón estéril, se introduce la muestra en el medio, agitando vigorosamente en el fondo del tubo AMIES con carbón activado. Este procedimiento se debe realizar cerca de un mechero para evitar contaminación del mismo, luego se cierran los tubos a presión con su respectiva tapa.

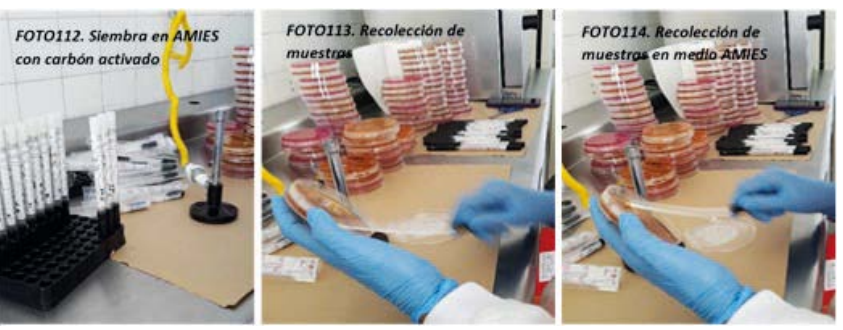

Figura 8. Siembra y recolección de las muestras en AMIES con carbón activado. Fuente: Elaboración propia, 2017.

Los medios de transporte AMIES con carbón activado ajustados y tapados se a incuban 48 horas para permitir que la colonia crezca y después de esto son embalados según las normas de bioseguridad y se envían a la ciudad de MONTERIA - CÓRDOBA, al laboratorio de Microbiología y Biología Molecular del Dr. Salim Mattar, quién gentilmente nos colaboró en su laboratorio. Para el análisis bioinformático de la amplificación de ADN se realizó una PCR convencional de las muestras aisladas de los microorganismos de la $M$. domestica como vector de enterobacterias y bacterias en general.

\section{Resultados y Discusión}

A las 30 muestras aisladas, purificadas y enviadas a Montería para el análisis Bioinformático, se les aisló el DNA y se hizo PCR (Reacción en cadena de polimerasa) obteniéndose los siguientes resultados: 
Tabla 1. Análisis comparativo de especies de microorganismos encontrados en los macerados de la mosca doméstica.

\begin{tabular}{|c|c|c|c|}
\hline & & MONTERIA & NEIVA \\
\hline Número & Código & Microorganismos & Microorganismos \\
\hline 1 & $1 \mathrm{~F}$ & E. coli & E. coli \\
\hline 2 & $1 \mathrm{NF}$ & $\begin{array}{l}\text { K. } \\
\text { pneumoniae; } \\
\text { Proteus }\end{array}$ & $\begin{array}{l}\text { Mezclada } \\
\text { con Proteus }\end{array}$ \\
\hline 3 & $2 \mathrm{~F}$ & E. coli & E. coli \\
\hline 4 & $2 \mathrm{~F} 1 \mathrm{ml}$ & E. coli & E. coli \\
\hline 5 & $3 F$ & E. coli & E. coli \\
\hline 6 & $3 \mathrm{NF}$ & $\begin{array}{l}\text { K. } \\
\text { pneumoniae }\end{array}$ & $\begin{array}{l}\text { Mezclada } \\
\text { con Proteus }\end{array}$ \\
\hline 7 & $4 \mathrm{~F}$ & $\begin{array}{l}\mathrm{K} . \\
\text { pneumoniae }\end{array}$ & $\begin{array}{l}\mathrm{K} . \\
\text { pneumoniae }\end{array}$ \\
\hline 8 & $4 \mathrm{NF}$ & $\begin{array}{l}\text { K. } \\
\text { pneumoniae; } \\
\text { Proteus }\end{array}$ & $\begin{array}{l}\text { Mezclada } \\
\text { con Proteus }\end{array}$ \\
\hline 9 & $5 \mathrm{~F}$ & E. coli & E. coli \\
\hline 10 & $5 \mathrm{NF}$ & $\begin{array}{l}\text { K. } \\
\text { pneumoniae }\end{array}$ & $\begin{array}{l}\text { K. } \\
\text { pneumoniae }\end{array}$ \\
\hline 11 & $6 \mathrm{~F}$ & E. coli & E. coli \\
\hline 12 & $6 \mathrm{NF}$ & $\begin{array}{l}\mathrm{K} \text {. } \\
\text { pneumoniae }\end{array}$ & $\begin{array}{l}\mathrm{K} . \\
\text { pneumoniae }\end{array}$ \\
\hline 13 & $7 \mathrm{~F}$ & E. coli & E. coli \\
\hline 14 & $8 \mathrm{~F}$ & $\begin{array}{l}\mathrm{K} . \\
\text { pneumoniae }\end{array}$ & E. coli \\
\hline 15 & $8 \mathrm{NF}$ & $\begin{array}{l}\text { K. } \\
\text { pneumoniae }\end{array}$ & $\begin{array}{l}\text { K. } \\
\text { pneumoniae }\end{array}$ \\
\hline
\end{tabular}

\begin{tabular}{|c|c|c|c|}
\hline 16 & $9 \mathrm{NF}$ & E. coli & E. coli \\
\hline 17 & $10 \mathrm{~F}$ & E. coli & E. coli \\
\hline 18 & $10 \mathrm{NF}$ & $\begin{array}{l}\text { K. } \\
\text { pneumoniae; } \\
\text { Proteus }\end{array}$ & $\begin{array}{l}\text { Mezclada } \\
\text { con Proteus }\end{array}$ \\
\hline 19 & $11 \mathrm{NF}$ & $\begin{array}{l}\text { K. } \\
\text { pneumoniae }\end{array}$ & $\begin{array}{l}\text { No } \\
\text { identificada }\end{array}$ \\
\hline 20 & $12 \mathrm{~F}$ & $\begin{array}{l}\text { K. } \\
\text { pneumoniae }\end{array}$ & $\begin{array}{l}\text { K. } \\
\text { pneumoniae }\end{array}$ \\
\hline 21 & $13 \mathrm{NF}$ & $\begin{array}{l}\text { K. } \\
\text { pneumoniae }\end{array}$ & $\begin{array}{l}\text { No } \\
\text { identificada }\end{array}$ \\
\hline 22 & $14 \mathrm{NF}$ & $\begin{array}{l}\text { K. } \\
\text { pneumoniae }\end{array}$ & $\begin{array}{l}\text { No } \\
\text { identificada }\end{array}$ \\
\hline 23 & $15 \mathrm{~F}$ & $\begin{array}{l}\text { K. } \\
\text { pneumoniae }\end{array}$ & $\begin{array}{l}\text { No } \\
\text { identificada }\end{array}$ \\
\hline 24 & $16 \mathrm{~F}$ & E. coli & E. coli \\
\hline 25 & $17 \mathrm{~F}$ & E. coli & $\begin{array}{l}\text { K. } \\
\text { pneumoniae }\end{array}$ \\
\hline 26 & $\begin{array}{c}17 \mathrm{~F} 0,5 \\
\mathrm{ml}\end{array}$ & $\begin{array}{l}\text { K. } \\
\text { pneumoniae }\end{array}$ & $\begin{array}{l}\text { K. } \\
\text { pneumoniae }\end{array}$ \\
\hline 27 & $\begin{array}{l}17 \mathrm{NF} \\
0,5 \mathrm{ml}\end{array}$ & $\begin{array}{l}\text { K. } \\
\text { pneumoniae; } \\
\text { Proteus }\end{array}$ & $\begin{array}{l}\text { Mezclada } \\
\text { con Proteus }\end{array}$ \\
\hline 28 & $18 \mathrm{~F}$ & $\begin{array}{l}\text { K. } \\
\text { pneumoniae }\end{array}$ & $\begin{array}{l}\text { K. } \\
\text { pneumoniae }\end{array}$ \\
\hline 29 & $\begin{array}{c}19 \mathrm{~F} 0,5 \\
\mathrm{ml}\end{array}$ & E. coli & E. coli \\
\hline 30 & $20 \mathrm{~F}$ & $\begin{array}{l}\text { K. } \\
\text { pneumoniae }\end{array}$ & $\begin{array}{l}\text { No } \\
\text { identificada }\end{array}$ \\
\hline
\end{tabular}

$\mathrm{Al}$ analizar el cuadro comparativo de las cepas Neiva y los resultados de las mismas por PCR en que se procesaron por el método manual en Montería, podemos concluir lo siguiente:

Tabla 2. Relación de muestras de acuerdo a su importancia y nivel de purificación y concordancia.

\begin{tabular}{|lc|}
\hline $\begin{array}{l}\text { Concordancia } \\
\text { correspondiente a 18 muestras }\end{array}$ & $60.00 \%$ \\
\hline $\begin{array}{l}\text { Muestras no puras o mezcladas } \\
\text { correspondiente a 5 muestras }\end{array}$ & $16,667 \%$ \\
\hline $\begin{array}{l}\text { Muestras no identificadas } \\
\text { correspondiente a 5 muestras }\end{array}$ & $16.667 \%$ \\
\hline $\begin{array}{l}\text { Muestras que no coinciden } \\
\text { correspondiente a 2 muestras }\end{array}$ & $6.667 \%$ \\
\hline
\end{tabular}


Como se observa en la tabla 1 hay 18 muestras con concordancia, que es mayor a un $50 \%$ como lo expresa la tabla 2, obteniéndose un resultado muy satisfactorio y positivo. Dentro de las muestras no puras o mezcladas, se encuentra 5 muestras equivalente a un $16,66 \%$, de las cuales también hay un grado de relación o concordancia.

Así mismo las muestras que no se lograron identificar, corresponden a 5 equivalente a un $16,66 \%$, no fueron identificadas porque se tuvo duda al realizar la coloración de Gram con respecto a los microorganismos observados al microscopio y sus reacciones bioquímicas no fueron totalmente claras.

La siembra, el aislamiento e identificación de los microorganismos por el método convencional es equivalente al realizado por PCR, esto se afirma porque los resultados obtenidos de los microorganismos encontrados son exactamente los mismos. A pesar de que los recursos disponibles no fueron suficientes, se distribuyeron adecuadamente para que esta investigación fuera posible.

Ahora con respecto a la obtención de las cepas de importancia epidemiológica por confirmar, podemos observar lo siguiente:

Tabla 3. Relación de cepas de acuerdo a su importancia epidemiológica.

\begin{tabular}{|lr|}
\hline 12 cepas de E. coli, & correspondiendo a un $40 \%$. \\
\hline 13 cepas de Klebsiella, & correspondiendo a un $43.3 \%$ \\
\hline 5 cepas contaminadas, & correspondiendo a un $16.66 \%$ \\
\hline
\end{tabular}

Se observa que el porcentaje de Escherichia coli es muy significativo y da pie para buscar E. coli 0157:H7 de importancia Clínica, como nos lo indica Restrepo et al. 2003, es una cepa productora de toxina Shiga la cual provoca calambres abdominales y diarrea, que puede progresar en algunos casos a diarrea sanguinolenta (colitis hemorrágica). También puede generar fiebre y vómitos.

Ahora para la comparación de las vías de contaminación (alimentos-vector) de los productos alimenticios que se sirven en el restaurante, se realizó un paralelo de datos a partir de los estudios culminados de los alimentos expendidos en el restaurante y en los alrededores como cafetería y ventas ambulantes.

Con el estudio de alimentos expendidos en el restaurante y en los alrededores como cafetería y ventas ambulantes se obtuvo un total de 84 muestreos dando como resultado la aparición de 43 aislamientos, con la siguiente distribución: 13 aislamientos de E. coli, 17 de Klebsiella spp; 4 de Shigella spp, 2 de Salmonella spp, 2 de Proteus spp, 2 de Enterobacter spp, 1 de Tatumella ptyseos y 2 de levaduras.

Tabla 4. Cuadro comparativo de cepas de acuerdo a su importancia epidemiológica recolectadas del restaurante La Venada.

\begin{tabular}{|l|c|c|c|c|} 
& \multicolumn{2}{c|}{ Análisis en Alimentos } & \multicolumn{2}{c|}{$\begin{array}{c}\text { Análisis en mosca } \\
\text { domestica }\end{array}$} \\
\hline Microorganismos & Frecuencia & Porcentaje & Frecuencia & Porcentaje \\
\hline E. coli & 13 & 25 & 12 & 40 \\
\hline Klebsiella & 17 & 40 & 13 & 43,33 \\
\hline Proteus & 2 & 0 & 5 & 16,66 \\
\hline
\end{tabular}

Escherichia coli se detectó tanto en el grupo de las comidas preparadas en los restaurantes de la Universidad como en las ventas ambulantes de los alrededores con un (25\%).

Nos da una clara evidencia de contaminación por este microorganismo, así como su capacidad para ser transportada por un vector como la mosca, se revela un porcentaje de alrededor del $(40 \%)$, frente a esto observamos cómo se transfiere de un huésped a otro y su capacidad de adaptabilidad frente a cualquier situación.

Para el caso de la Klebsiella spp se aisló en la mayoría de las comidas preparadas en las ventas ambulantes y en los restaurantes dela Universidad con un $(40 \%)$. Frente al $(43,33 \%)$ encontrado en la mosca, indicándonos que este puede encontrarse no solo en los humanos sino también en un insecto que pudo haber contaminado la comida al posarse sobre ella.

Para el caso de Proteus spp se aisló a partir de dos jugos naturales y arepas de maíz, procedentes de las ventas ambulantes que se encuentran a las afueras de la Universidad, es representado 
en un porcentaje del $11 \%$. De la cafetería y el restaurante de la Universidad no se aisló este microorganismo. Frente a un $(16,66 \%)$ indicando que este microorganismo si vive como huésped en la mosca y es capaz de contaminar cualquier tipo de comida debido a que es transportado por el insecto el cual lo transfiere por la regurgitación al posarse sobre el alimento que se encuentra servido en los platos y que puede causar una intoxicación en las personas que toman el servicio de alimentación en el restaurante.

Ahora para la elaboración del material de divulgación, de la cartilla y/o folletos estos surgen de la necesidad de crear conciencia y enseñar a la comunidad educativa en el manejo de las técnicas correctas de asepsia y en la preparación de los alimentos, para prevenir su contaminación al ser consumidos en el servicio de alimentación del restaurante estudiantil La Venada, donde se trabajó en conjunto con Bienestar Universitario al hacer una campaña masiva divulgando la información recolectada de este proyecto de investigación y los efectos que producen estos microorganismos en la salud humana.

\section{Conclusiones}

Esta investigación permitió comprender la importancia de conocer cuáles son los problemas de salud en los que se ven afectados tanto estudiantes, y comunidad en general, frente a la mala manipulación de los alimentos, utensilios y la propagación de los insectos vector como lo es la mosca.

Observamos que se ha presentado una seria problemática en los últimos años del servicio que brinda el restaurante La Venada, situación que conlleva incluso a analizar, por qué no se han tomado las medidas necesarias de control, frente a la calidad del servicio que presta a la universidad y cómo se ve afectada la imagen de la misma, frente a su déficit en el manejo de estas situaciones.

Por medio de este trabajo determinamos la presencia de enterobacterias presentes en la M. doméstica como vector de propagación de enfermedades en el Restaurante La Venada de la
Universidad Surcolombiana sede Central Neiva Huila, en la que se encontró un porcentaje relativo de Escherichia Coli con un $40 \%$ en 12 muestras recolectadas, un $43,33 \%$ de Klebsiella spp en 13 muestras recolectadas y un $16,66 \%$ de Proteus spp en 5 muestras recolectadas.

Se estimaron los tamaños poblacionales de los microorganismos objeto de estudio presentes en la M. doméstica al encontrarse estos microorganismos de importancia clínica como lo es la E. coli, la Klebsiella spp, y el Proteus spp, indicando que este insecto es un claro vector de propagación de enfermedades que causa múltiples infecciones como diarrea, vómito, malestar general, calambres abdominales o cólicos y fiebre como síntomas claros de intoxicación en los seres humanos.

A partir de la siembra en agar MacConkey por la técnica de agotamiento, se aislaron los microorganismos, y se repicaron para obtener el cultivo purificado o axénico. Con el análisis microbiológico, pruebas bioquímicas y con la amplificación de la cadena de $\mathrm{ADN}$ por la prueba convencional de reacción en cadena de la polimerasa PCR, se identificaron los microorganismos de interés presentes en el vector M. doméstica en el restaurante La Venada, como E. coli, Klebsiella spp, y Proteus spp.

Por las vías de contaminación (alimentosvector) de los productos alimenticios que se sirven en el restaurante, se reconoció el efecto que producen estos microorganismos en la salud humana mediante una comparación de datos analizados a partir del estudio terminado en análisis microbiológico de alimentos del restaurante y sus alrededores, como de la mosca doméstica que porta estos microorganismos, encontrándose similitud de los mismos, identificados por pruebas convencionales de PCR y su alto índice de infestación y propagación.

La comunidad universitaria se concientizó gracias a la recolección de toda la información producida en este proyecto de investigación y su divulgación se hizo a partir de la cartilla y de los folletos que ilustraron el manejo de las técnicas correctas de asepsia, manipulación de alimentos, utensilios y las basuras provenientes de los 
mismos para prevenir la contaminación, al hacer uso del servicio de alimentación en el restaurante estudiantil La Venada y así evitar una futura intoxicación por este vector.

\section{Referencias bibliográficas e infográficas}

Alam, M.; Zurek, L. (2004). Association of Escherichia coli O 157: H7 with houseflies on a cattle farm. Appl. Environ. Microbiol. 70(12):7578-7580.

Alexopoulos, C.; Mims, C. (1985). Introducción a la micología. Barcelona: Ediciones Omega.

Almeida, C. R. (2006). Contaminación Microbiana de los Alimentos vendidos en la vía pública en ciudades de América Latina y características socio-económicas de sus vendedores $y$ consumidores. New York:OPS/OMS, División de Prevención y Control de Enfermedades.

Basualdo W, Allende I, Cabrera T, Arboleda Sosa A. (2001). Estudio de brote de diarrea disentérica por Shigella sp. en una comunidad rural. Arch Pediatr Uruguay 72(1): 65-71.

Bejar, V., Chumpitaz, J., Pareja, E., Valencia, E., Huamán, A., Sevilla, C., Tapia, M., \& Sáez, G. (2006). Musca domestica como vector mecánico de bacterias entero patógenas en mercados y basurales de Lima y Callao. Rev. Perú Med. Exp. Salud Pública. 23(1), pp.39-43.

Bonifaz, A. (2010). Micología Médica básica. Miami: Mc Graw-Hill editors.

Cárdenas, M. \& Martínez, R. (2004). Protozoarios parásitos de importancia en Salud Pública transportados por M. domestica Linnaeus en Lima, Perú. Rev. Perú Biología 11(2), pp.149-152.

Castillo, C., Castro, M., Carhuapoma, C., Castro, H., Castro, R., \& Chambi, J. (2008). Parásitos de importancia en salud pública transportados por M. doméstica. LimaPerú. CIMEL 13(2), pp. 49-53.
Fotedar, R., Banerjee, U., Samantry, J., \& Shiniwa, U. (1992). Vector potential of hospital houseflies with special reference to Klebsiella species. Epidemiol. Infect 109(1):143- 147.

Gambirazio, C. (2002). Control Sanitario de Alimentos Expendidos en la Vía Pública. Inf. Téc. FAO/DIGESA, Proyecto TCP/ PER/0155(T), Lima, Perú.

Graczyk, T., Knight, R., \& Tamang, L. (2005). Mechanical transmission of human protozoan parasites by insects. Clinic. Microbiol. Rev 18(1):128-132.

Harwood, R. F. and M. T. James. (1979). Entomology in human and animal health. New York: MacMillan Publishing Co.

Legner, E. F. (1995). Biological control of diptera of medical and veterinary importance. $J$. Vector Ecol. pp. 59-120.

Luzmilla A., Flores E., Mendoza G., Mundarain T., (2007). Asociación de Klebsiella spp., con síndrome diarreico agudo en niños de 0 a 2 años de edad. Revista de la Facultad de Ciencias de la Salud. Universidad de Carabobo.

Manrique, P.; Delfín, H. (1997). Importancia de las moscas como vectores potenciales de enfermedades diarreicas en humanos. Biomédica 8:163-170.

Moissant, E.; Tkachuk, O.; Roman, R. (2004). Deᄀtección de agentes bacterianos en adultos de Musca domestica (Diptera: Muscidae) recolectadas en Maracay, Estado Aragua, Venezuela. Entomotrópica 19(3):161164.

Moriya, K., Fujybayashi, T., Yoshihara, A., Matsuda, N., Sumi, N., Umezaki, H., Kurahashi, N., Aqui, A., Wada, H., \& Watanabe, A. (1999). Verotoxin-producing Escherichia coli O157:H7 carried by the housefly in Japan. Med. Vet. Entomol 13, pp. 214-216. 
Murray, P., Rosenthal, K., Koayashi, G., \& Pfaller, M. (2002). Medical Microbiology. St. Luis, Missouri: Mosby Inc. (Elsevier Science).

Nunes, M. (2002). Isolation of fungi in Musca domestica Linnaeus, 1758 (Diptera: Muscidae) captured at two natural breeding grounds in the municipality of Seropedica, Rio de Janeiro, Brazil. Mem Inst. Oswaldo Cruz, Rio de Janeiro. 97(8):1107-1110.

Olarte, J. (1998). Etiopatogenia de las diarreas infecciosas. Bio. Med. Hosp. Infant. Me. 42: 266- 271.

Quiroz, R. H. (1990). Parasitología y Enfermedades Parasitarias de los Animales Domésticos, Infestaciones por moscas y mosquitos. México D.F.: Ed. Limusa.

Restrepo, A., Robledo, J., Leiderman, E., Restrepo, M., Botero, D., \& Bedoya, V. (2003). Fundamentos de Medicina -Enfermedades Infecciosas. México D.F.: Corporación para investigaciones Biológicas.

Salazar, S. A. (1981). Dinámica poblacional de larvas y adultos de mosca domestica (Díptera: Muscidae) en granjas del municipio de Ramos Arizpe, Coah. Tesis de licenciatura. División de Agronomía de la Universidad Autónoma Agraria Antonio Narro, Saltillo, Coahuila.

Ugbogu, O., Nwachukwv, N., \& Ogbuagu, V. (2006). Isolation of Salmonella and Shigella species from house flies (Musca domestica) in Uturu, Nigeri. Afr. J. Biotech. 5(11), pp.10901091.

Vera, J. y B. Domínguez. (1985). Biología, hábitos y control de moscas de los establos lecheros. Memorias de la Primera Conferencia Internacional sobre Ganado Lechero. Méx. D.F. pp. 49-58. 